\title{
Role of Gal-3 and H-FABP in the early diagnosis of acute coronary syndrome
}

\author{
Atay $\mathrm{E}^{1}$, Guzel $\mathrm{M}^{1}$, Amanvermez $\mathrm{R}^{2}$, Demir $\mathrm{MT}^{1}$, Erenler $\mathrm{AK}^{3}$, Ozgen $\mathrm{E}^{1}$, Yucel $\mathrm{M}^{1}$ \\ Department of Emergency Medicine, Samsun Training and Research Hospital, Samsun, Turkey. \\ drmuratguzel@gmail.com
}

\begin{abstract}
OBJECTIVES: We aimed to compare the plasma levels of biomarkers such as: serum Gal-3, H-FABP, cTnl, and $\mathrm{CK}-\mathrm{MB}$ in patients, who were admitted to the emergency room with chest pain, and to determine whether these biomarkers have early diagnostic value of acute coronary syndrome (ACS).

METHODS: The study was performed in 60 patients aged $\geq 18$ years, who were admitted to emergency room. These patients were divided into 3 groups: patients with STEMI (group I, $n=20$ ), patients with NSTEMI (group II, $n=20$ ), and patients with USAP (group III, $n=20$ ). Serum Gal-3, H-FABP, cTnl, and CK-MB levels were measured at admission, and at the 2 nd and 4th hours.

RESULTS: There were statistically significant differences between the groups in terms of Gal-3 levels at admission, and the 2nd and 4th hours ( $p=0.007, p=0.002$, and $p=0.001$, respectively). There were statistically significant differences between the groups in terms of H-FABP levels at admission, and the 2nd and 4th hours $(p=0.001, p=0.003$, and $p=0.003$, respectively). There were statistically significant differences between the groups in terms of cTnl levels at admission, and the 2nd and 4th hours $(p<0.001, p<0.001$, and $p<0.001$, respectively).

CONCLUSIONS: According to the results of the study, cTnl, H-FABP, and Gal-3 are useful parameters that can be used in the early diagnosis of ACS (Tab. 4, Ref. 36). Text in PDF www.elis.sk. KEY WORDS: acute coronary syndromes, emergency room, galectin-3, heart-type fatty acid-binding protein.
\end{abstract}

\section{Introduction}

Early diagnosis and treatment of life-threatening acute coronary syndromes (ACS) such as: ST elevation and acute myocardial infarction (STEMI), non-ST-elevation myocardial infarction (NSTEMI) and unstable angina pectoris (USAP) are important (1). Early diagnosis is very important in patients with ACS in order to reduce morbidity and mortality. To prevent unnecessary hospitalization and inappropriate discharges from hospital, new cardiac biomarkers are needed to show myocardial cell damage earlier. Therefore, in the diagnosis of acute myocardial infarction (AMI), measurements of cardiac troponin are also used besides electrocardiography (ECG). Heart-specific structural proteins are cardiac troponins (cTn), which are sensitive and specific markers of myocardial damage (2). In AMI, cTnI and cTnT are released from the damaged myocardium, both as unspoiled proteins and as spoilage products. Detection of cTn in peripheral blood indicates cardiomyocyte damage. Cardiac troponins are more sensitive and

${ }^{1}$ Department of Emergency Medicine, Samsun Training and Research Hospital, Samsun, Turkey, ${ }^{2}$ Department of Medical Biochemistry, Faculty of Medicine, Ondokuz Mayis University, Samsun, Turkey, and ${ }^{3}$ Department of Emergency Medicine, Hitit University, Corum, Turkey

Address for correspondence: M. Guzel, Department of Emergency Medicine, Samsun Training and Research Hospital, Samsun, Turkey.

Phone: +90.533 .6143492$ specific cardiomyocyte injury markers than creatine kinase (CK), creatine kinase $\mathrm{MB}$ isoenzyme (CK-MB), and myoglobin.

Cardiac troponins are biologic markers of high sensitivity and specificity in demonstrating myocardial damage. However, it is known that troponin can be elevated in many different clinical situations other than ACS, such as: acute or chronic congestive heart failure, pulmonary embolism, and inflammatory heart diseases (pericarditis, myocarditis, endocarditis). It is also reported that a certain time has to pass to determine high troponin levels in the plasma associated with ACS (3).

In some studies in literature, it is reported that Galectin-3 (Gal-3) and heart-type fatty acid-binding protein (H-FABP), two of the new cardiac biomarkers, may be used in the diagnosis of ACS (4). H-FABP is a low-molecular-weight protein composed of 132 amino acids, which plays a role in myocardial fatty acid metabolism. H-FABP represents a transport protein family that allows fatty acids to be transported through membranes specific to tissue. Plasma levels of H-FABP, which is found in large amounts in cardiomyocytes and in small amounts in brain, kidney and skeletal tissue, may increase in response to acute ischemic stroke and intensive exercise. It is released quickly into the cytosole in AMI.

Gal-3 is a glycoprotein binding, a $26-\mathrm{KDa}$ lectin family protein secreted by activated cardiac macrophages. Plasma Gal-3 can predict cardiovascular death in patients with high risk, who are admitted for coronary angiography. Gal-3 is an independent risk factor for coronary artery disease (CAD) and an increase of an 
average of $8.8 \mathrm{ng} / \mathrm{mL}$ in Gal-3 concentration detected during the mid-term follow-up in patients with $\mathrm{MI}$ is an independent predictor for mortality $(5,6)$.

Our aim in this study was to determine the efficacy of Gal-3, $\mathrm{H}-\mathrm{FABP}$, troponin I, and CK-MB in the early diagnosis of ACS in patients admitted to the emergency room with chest pain.

\section{Materials and methods}

This prospective study was initiated after the approval of the Ethics Committee of Ondokuz Mayis University (date 13.07.2017, number B.3O.2ODM.0.20.08/10571103). Into this study, 60 patients aged $\geq 18$ years, who were admitted to the emergency room of Samsun Training and Research Hospital with sudden-onset chest pain and who were diagnosed with acute coronary syndrome were included. Patients with renal insufficiency, collagen tissue disease, active infection, vasculitis, patients with psychiatric diseases such as: depression or somatization disorder, and patients with previous coronary angioplasty, coronary by-pass surgery, and open heart surgery were excluded from the study. In the pre-study sample size analysis $(d=1.25, o=1.1, \alpha=0.05$, power $=0.80)$, the minimum number for the sample size was calculated as $\mathrm{n}=$ 18 for each group. Twenty patients were planned to be included in each group in the study. Patients were divided into three groups.

Group 1: Patients with unstable angina pectoris $(n=20)$. This group consisted of patients with typical chest pain lasting more than 20 minutes with new-onset or increasing frequency in the last two months with no increase in cTnI levels.

Group 2: Patients with MI with acute ST segment elevation in ECG $(n=20)$. Patients in this group had typical chest pain lasting more than 30 minutes and had ST segment elevation ( $2 \mathrm{~mm}$ in the chest, $1 \mathrm{~mm}$ in the extremity leads) at two or more leads in ECG.

Group 3: Patients with MI without ST segment elevation in ECG $(n=20)$. Patients in this group had typical chest pain lasting more than 30 minutes, ST segment depression and T wave negativity in ECG, and elevated cTnI levels.

Three blood samples were taken from the patients: at admission, and at the 2 nd and 4 th hour after admission. After centrifuging the blood samples of the patients for 10 minutes at 3500 RPM, plasma was separated and stored in a freezer at $-70{ }^{\circ} \mathrm{C}$. On the day of measurement, plasma samples were removed from the deep freezer and were left to defrost. After the plasma samples were defrosted, levels of biomarkers were measured according to the study principle in the kit. Simultaneously, plasma CK-MB, cTnI, Gal-3, and H-FABP levels were measured.

\section{Measurement of serum cTnI level}

Measurements were performed using a solid-phase radial partition enzyme immunoassay, which is a sandwich-type assay. After centrifuging the blood sample for 10 minutes at 4000 RPM, plasma was separated and loaded to the Siemens ADVIA Centaur CP Immunoassay System. In this procedure, monoclonal cTnI antibodies (AB) linked to solid phase were at the central point of the glass fiber paper in the test package. Then, enzyme-labelled Ab that binds specifically to a different antigenic region of the cTnI molecule was added. In this second incubation period, enzymelabeled Abs complex with cTnI antigens bound with $\mathrm{Ab}$ in the solid phase (Ab-cTnI-enzyme-labeled Ab complex). Unbound labelled-Abs were removed by washing. The washing solution contained a substrate (Lumi Phos* 530) that was used in labelling $\mathrm{Ab}$ and generated a luminescent product with alkaline phosphatase (ALP) activity.

\section{Measurement of serum H-FABP and Gal-3 levels}

Serum GAL-3 and H-FABP levels were measured using commercial enzyme-linked immunosorbent assay (ELISA) kits (Gal3 Human Elisa Kit/Sunredbio Band Product Code: 201-12-1952, H-FABP Human Elisa Kit/Sunredbio Band Product Code: 20112-1214). During the measurement, plates that were coated with specific antibodies to Gal-3 and H-FABP were used. The samples and standards were placed in the wells of the plates. The Gal-3 and H-FABP molecules found in serum and standards were incubated to bind to the antibodies. Then, biotin-conjugated galectine and H-FABP-specific antibody were added into the Ab-Gal-3 and Ab-H-FABP complexes. After this process, color formation was achieved with the addition of Avidin-conjugated horseradish peroxidase (HRP) and TMB substrate. The reaction was stopped by adding a stop solution and the color was measured using a spectrophotometer at $450 \mathrm{~nm}$ wavelength. The concentrations of samples were determined according to the absorbance concentration graph formed according to the standards. The results are given as $\mathrm{ng} / \mathrm{mL}$.

\section{Statistical analysis}

The Statistical Package for Social Sciences (SPSS) for Windows 22.0 (SPSS Inc, Chicago, IL) software package was used for statistical analysis. Descriptive statistics are expressed as the mean \pm standard deviation, median (minimum-maximum), frequency distribution, and percentages with tables. Pearson's Chi-square test was used to evaluate categorical variables. The suitability of variables for normal distribution was studied using visual (histogram and probability graphs) and analytical methods (ShapiroWilk test). The Kruskal-Wallis test was used to make comparisons between three independent groups containing variables without normal distribution. The Mann-Whitney U test with Bonferroni correction in post-hoc paired comparisons was used to determine the source of the difference, when a significant difference was detected. The Friedman test was used to make comparisons between three dependent groups. The Wilcoxon signed-rank test with Bonferroni correction in post-hoc paired comparisons was used to determine the source of the difference when a significant difference was detected. The Spearman test was used to compare the relation between variables. Correlation coefficients of $0-0.25$ were accepted as weak, $0.26-0.50$ as moderate, $0.51-0.75$ as strong, and $0.76-1.00$ as very strong relations. $\mathrm{p}$ value $<0.05$ was considered statistically significant.

\section{Results}

The mean age of the patients included in the study was 63.6 $\pm 13.5(\min 31-\max 88)$ years. Seventy percent were males (n 
Tab. 1. The distribution of CK-MB, cTnI, Gal-3, and H-FABP levels at admission, and the $2^{\text {nd }}$ and $4^{\text {th }}$ hours between the three study groups and within each group.

\begin{tabular}{|c|c|c|c|c|c|c|c|c|}
\hline & & \multicolumn{2}{|c|}{ USAP $(n=20)$} & \multicolumn{2}{|c|}{ STEMI $(\mathrm{n}=20)$} & \multicolumn{2}{|c|}{ NSTEMI $(\mathrm{n}=20)$} & \multirow[t]{2}{*}{$\mathbf{p}^{*}$} \\
\hline & & mean \pm SD & median $(\min -\max )$ & mean \pm SD & median $(\min -\max )$ & mean \pm SD & median $(\min -\max )$ & \\
\hline \multirow{4}{*}{$\begin{array}{l}\text { CK-MB } \\
\text { (ng/mL) }\end{array}$} & 0 hours & $3.4 \pm 4.9^{b}$ & $2.1^{\mathrm{b}}(0.7-23.6)$ & $38.6 \pm 67.8$ & $10.6(0.6-300)$ & $18.2 \pm 40.4$ & $4.7(0.5-136)$ & 0.001 \\
\hline & $2^{\text {nd }}$ hour & $3.1 \pm 4.0^{\mathrm{bc}}$ & $2.2^{\mathrm{bc}}(0.4-19.4)$ & $82.7 \pm 105.5$ & $45.6(2.4-300)$ & $29.7 \pm 71.2$ & $7.2(1-300)$ & $<0.001$ \\
\hline & $4^{\text {th }}$ hour & $\mathrm{xy} 2.8 \pm 3.8^{\mathrm{bc}}$ & ${ }^{\mathrm{xy}} 1.8^{\mathrm{bc}}(0.3-18.4)$ & ${ }^{\mathrm{xy}} 125.5 \pm 117.8^{\mathrm{c}}$ & xy $81.8^{\mathrm{c}}(3.2-300)$ & $30.0 \pm 67.2$ & $7.6(1.4-300)$ & $<0.001$ \\
\hline & $p^{* k *}$ & \multicolumn{2}{|r|}{$<0.001$} & \multicolumn{2}{|c|}{$<0.001$} & \multicolumn{2}{|c|}{0.419} & \\
\hline \multirow{4}{*}{$\begin{array}{l}\text { cTnI } \\
(\mathrm{ng} / \mathrm{mL})\end{array}$} & 0 hours & $0.01 \pm 0.01^{\mathrm{bc}}$ & $0(0-0.03)^{\mathrm{bc}}$ & yz $9.1 \pm 13.8$ & ${ }^{\mathrm{yz}} 0.86(0-50)$ & $4.2 \pm 11.7$ & $0.14(0-50)$ & $<0.001$ \\
\hline & $2^{\text {nd }}$ hour & $0.01 \pm 0.01^{\mathrm{bc}}$ & $0(0-0.03)^{\mathrm{bc}}$ & $20.2 \pm 20.5$ & $12.5(0-50)$ & $5.7 \pm 14.4$ & $0.40(0-50)$ & $<0.001$ \\
\hline & $4^{\text {th }}$ hour & $0.01 \pm 0.01^{\mathrm{bc}}$ & $0(0-0.05)^{\mathrm{bc}}$ & $28.6 \pm 20.8$ & $32.1(0-50)$ & $10.2 \pm 18.2$ & $0.54(0-52)$ & $<0.001$ \\
\hline & $p^{k * k}$ & \multicolumn{2}{|r|}{0.135} & \multicolumn{2}{|c|}{$<0.001$} & \multicolumn{2}{|c|}{0.079} & \\
\hline \multirow{5}{*}{ Gal-3 } & 0 hours & $4.5 \pm 4.4^{\mathrm{bc}}$ & $2.9(0-20.2)^{\mathrm{bc}}$ & $10.0 \pm 12.6$ & $7.6(0-58.6)$ & $9.2 \pm 7.9$ & $7.6(0-36.8)$ & 0.007 \\
\hline & $2^{\text {nd }}$ hour & $4.3 \pm 5.3^{\mathrm{bc}}$ & $2.8(0-21.2)^{\mathrm{bc}}$ & $11.8 \pm 12.6$ & $9.0(2.2-52.6)$ & $9.0 \pm 6.2$ & $8.6(0-281)$ & 0.002 \\
\hline & $4^{\text {th }}$ hour & $4.2 \pm 5.9^{\mathrm{bc}}$ & $2.4(0-25.4)^{\mathrm{bc}}$ & $9.9 \pm 13.1$ & $7.4(0.5-62.1)$ & $10.4 \pm 6.7$ & $10.0(0-32.5)$ & 0.001 \\
\hline & $\boldsymbol{p}^{* * *}$ & \multicolumn{2}{|r|}{0.564} & \multicolumn{2}{|c|}{0.157} & \multicolumn{2}{|c|}{0.128} & \\
\hline & 0 hours & $3.9 \pm 2.9$ & $3.1(0.6-12.4)$ & $4.3 \pm 3.8$ & $3.2(0.6-15.5)$ & $1.7 \pm 1.0$ & $1.5^{\mathrm{ab}}(0.5-4.6)$ & 0.001 \\
\hline \multirow[t]{2}{*}{ H-FABP } & $2^{\text {nd }}$ hour & $4.1 \pm 3.2$ & $3.3(0.7-14.8)$ & $4.0 \pm 3.6$ & $2.9(0.3-14.0)$ & $1.9 \pm 1.1$ & $1.6^{\mathrm{ab}}(0.6-4.8)$ & 0.003 \\
\hline & $4^{\text {th }}$ hour & $4.0 \pm 3.4$ & $3.2(0.4-15.5)$ & $4.0 \pm 3.5$ & $3.0(0.9-13.3)$ & $1.8 \pm 1.0$ & $1.5^{\mathrm{ab}}(0.6-4.8)$ & 0.003 \\
\hline
\end{tabular}

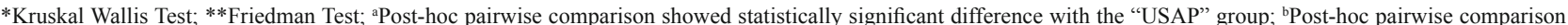
showed statistically significant difference with the "STEMI" group; cPost-hoc pairwise comparison showed statistically significant difference with the "NSTEMI" group;

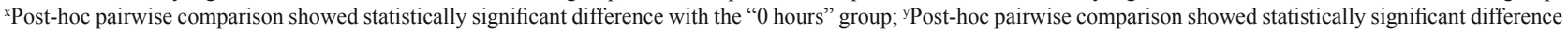
with the "2nd hour" group; ${ }^{2}$ Post-hoc pairwise comparison showed statistically significant difference with the "4th hour" group.

$=42)$ and $30 \%$ were females $(n=18)$. There was no significant difference between the study groups in terms of age and sex $(\mathrm{p}=$ 0.134 and $\mathrm{p}=0.788$, respectively).

The values of CK-MB, cTnI, Gal-3 and H-FABP at admission, and the 2 nd and 4 th hours in each group are presented in Table 1.

There were statistically significant differences between the groups in terms of cTnI levels at admission, and at the 2nd and 4 th hours ( $\mathrm{p}<0.001, \mathrm{p}<0.001$, and $\mathrm{p}<0.001$, respectively). Post-hoc pairwise comparisons revealed that the significant difference was due to the USAP group. cTnI levels at admission, and the 2 nd and 4th hours were significantly lower in the USAP group than in the STEMI and NSTEMI groups. No statistical difference was found between Gal-3 levels at admission and the 2nd and 4th hours within each group $(\mathrm{p}>0.05)$, whereas there was a statistically significant difference between the USAP, STEMI and NSTMEI groups $(p=0.007, p=0.002$, and $p=0.001$, respectively). Post-hoc pairwise comparisons revealed that the significant difference was due to the USAP group. There were statistically significant differences between the groups in terms of H-FABP levels at admission and the 2nd and 4th hours ( $\mathrm{p}=$ $0.001, p=0.003$, and $p=0.003$, respectively). Post-hoc pairwise comparisons revealed that the significant difference was due to the NSTEMI group. No statistical difference was found between H-FABP levels at admission, and the 2nd and 4th hours within each group $(p>0.05)$.

The relation between CK-MB, cTnI, Gal-3, and H-FABP values in the groups are presented in the Table 2.

There was a strong and positive, statistically significant relation between CK-MB and cTnI levels at admission in patients with STEMI $(r=0.80, p<0.001)$; no relation was found between other cardiac biomarker levels at admission $(p>0.05)$. There was
Tab. 2. The relationship between CK-MB, cTnI, Gal-3, and H-FABP levels at admission within each study group.

\begin{tabular}{|c|c|c|c|c|c|c|}
\hline 0.hour & & & CK-MB & cTnI & Gal-3 & H-FABP \\
\hline \multirow{8}{*}{$\begin{array}{l}\text { USAP } \\
(\mathrm{n}=20)\end{array}$} & \multirow{2}{*}{ CK-MB } & $\mathrm{R}$ & 1.000 & 0.345 & 0.065 & -0.137 \\
\hline & & $\mathrm{P}$ & . & 0.137 & 0.785 & 0.565 \\
\hline & \multirow{2}{*}{ cTnI } & $\mathrm{R}$ & 0.345 & 1.000 & 0.020 & $0.508^{*}$ \\
\hline & & $\mathrm{p}$ & 0.137 & . & 0.934 & 0.022 \\
\hline & \multirow{2}{*}{ Gal-3 } & $\mathrm{R}$ & 0.065 & 0.020 & 1.000 & 0.066 \\
\hline & & $\mathrm{p}$ & 0.785 & 0.934 & . & 0.782 \\
\hline & \multirow{2}{*}{ H-FABP } & $\mathrm{R}$ & -0.137 & $0.508^{*}$ & 0.066 & 1.000 \\
\hline & & $\mathrm{p}$ & 0.565 & 0.022 & 0.782 & 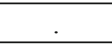 \\
\hline \multirow{8}{*}{$\begin{array}{l}\text { STEMI } \\
(\mathrm{n}=20)\end{array}$} & \multirow{2}{*}{ CK-MB } & $\mathrm{R}$ & 1.000 & $0.806^{* *}$ & 0.094 & -0.045 \\
\hline & & $\mathrm{P}$ & . & $<0.001$ & 0.693 & 0.850 \\
\hline & \multirow{2}{*}{ cTnI } & $\mathrm{R}$ & $0.806^{* *}$ & 1.000 & 0.063 & 0.132 \\
\hline & & $\mathrm{P}$ & $<0.001$ & - & 0.792 & 0.578 \\
\hline & \multirow{2}{*}{ Gal-3 } & $\mathrm{R}$ & 0.094 & 0.063 & 1.000 & 0.147 \\
\hline & & $\mathrm{P}$ & 0.693 & 0.792 & . & 0.535 \\
\hline & \multirow{2}{*}{ H-FABP } & $\mathrm{R}$ & -0.045 & 0.132 & 0.147 & 1.000 \\
\hline & & $\mathrm{P}$ & 0.850 & 0.578 & 0.535 & \\
\hline \multirow{8}{*}{$\begin{array}{l}\text { NSTEMI } \\
(\mathrm{n}=20)\end{array}$} & \multirow{2}{*}{ CK-MB } & $\mathrm{R}$ & 1.000 & $0.802^{* *}$ & -0.004 & 0.031 \\
\hline & & $\mathrm{P}$ & . & $<0.001$ & 0.987 & 0.897 \\
\hline & \multirow{2}{*}{ cTnI } & $\mathrm{R}$ & $0.802^{* *}$ & 1.000 & 0.019 & 0.154 \\
\hline & & $\mathrm{P}$ & $<0.001$ & . & 0.937 & 0.517 \\
\hline & \multirow{2}{*}{ Gal-3 } & $\mathrm{R}$ & -0.004 & 0.019 & 1.000 & 0.370 \\
\hline & & $\mathrm{P}$ & 0.987 & 0.937 & . & 0.109 \\
\hline & \multirow{2}{*}{ H-FABP } & $\mathrm{R}$ & 0.031 & 0.154 & 0.370 & 1.000 \\
\hline & & $\mathrm{P}$ & 0.897 & 0.517 & 0.109 & 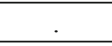 \\
\hline
\end{tabular}

r:Spearman Correlation Coefficient

a strong and positive, statistically significant relation between CK-MB and cTnI levels admission in patients with NSTEMI ( $\mathrm{r}$ $=0.80, \mathrm{p}<0.001)$; no relation was found between other cardiac 
Tab. 3. The relationship between CK-MB, cTnI, Galectin-3 and HFABP levels at 2nd hour within each study group.

\begin{tabular}{|c|c|c|c|c|c|c|}
\hline 2.hour & & & CK-MB & cTnI & Gal-3 & H-FABP \\
\hline \multirow{8}{*}{$\begin{array}{l}\text { USAP } \\
(\mathrm{n}=20)\end{array}$} & \multirow{2}{*}{ CK-MB } & $\mathrm{r}$ & 1.000 & 0.298 & 0.296 & -0.213 \\
\hline & & $\mathrm{p}$ & . & 0.202 & 0.205 & 0.367 \\
\hline & \multirow{2}{*}{$\mathrm{cTnI}$} & $\mathrm{r}$ & 0.298 & 1.000 & -0.172 & $0.463^{*}$ \\
\hline & & $\mathrm{p}$ & 0.202 & . & 0.469 & 0.040 \\
\hline & \multirow{2}{*}{ Gal-3 } & $\mathrm{r}$ & 0.296 & -0.172 & 1.000 & 0.039 \\
\hline & & $p$ & 0.205 & 0.469 & . & 0.870 \\
\hline & \multirow{2}{*}{ H-FABP } & $\mathrm{r}$ & -0.213 & $0.463^{*}$ & 0.039 & 1.000 \\
\hline & & $\mathrm{p}$ & 0.367 & 0.040 & 0.870 & . \\
\hline \multirow{8}{*}{$\begin{array}{l}\text { STEMI } \\
(\mathrm{n}=20)\end{array}$} & \multirow{2}{*}{ CK-MB } & $\mathrm{r}$ & 1.000 & $0.803^{* *}$ & -0.125 & 0.173 \\
\hline & & $\mathrm{p}$ & . & $<0.001$ & 0.600 & 0.465 \\
\hline & \multirow{2}{*}{$\mathrm{cTnI}$} & $\mathrm{r}$ & $0.803^{* *}$ & 1.000 & -0.058 & -0.076 \\
\hline & & $\mathrm{p}$ & $<0.001$ & . & 0.809 & 0.751 \\
\hline & \multirow{2}{*}{ Gal-3 } & $\mathrm{r}$ & -0.125 & -0.058 & 1.000 & -0.161 \\
\hline & & $\mathrm{p}$ & 0.600 & 0.809 &. & 0.498 \\
\hline & \multirow{2}{*}{ H-FABP } & $\mathrm{r}$ & 0.173 & -0.076 & -0.161 & 1.000 \\
\hline & & $\mathrm{p}$ & 0.465 & 0.751 & 0.498 &. \\
\hline \multirow{8}{*}{$\begin{array}{l}\text { NSTEMI } \\
(\mathrm{n}=20)\end{array}$} & \multirow{2}{*}{ CK-MB } & $\mathrm{r}$ & 1.000 & $0.833^{* *}$ & 0.352 & -0.058 \\
\hline & & $\mathrm{p}$ &. & $<0.001$ & 0.128 & 0.808 \\
\hline & \multirow{2}{*}{$\mathrm{cTnI}$} & $\mathrm{r}$ & $0.833^{* *}$ & 1.000 & 0.442 & -0.068 \\
\hline & & $\mathrm{p}$ & $<0.001$ & . & 0.051 & 0.777 \\
\hline & \multirow{2}{*}{ Gal-3 } & $\mathrm{r}$ & 0.352 & 0.442 & 1.000 & 0.183 \\
\hline & & $\mathrm{p}$ & 0.128 & 0.051 & . & 0.439 \\
\hline & \multirow{2}{*}{ H-FABP } & $\mathrm{r}$ & -0.058 & -0.068 & 0.183 & 1.000 \\
\hline & & $\mathrm{p}$ & 0.808 & 0.777 & 0.439 & 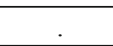 \\
\hline
\end{tabular}

r:Spearman Correlation Coefficient

biomarker levels at admission ( $\mathrm{p}>0.05)$. There was a strong, statistically significant relation between cTnI and H-FABP levels at admission in patients with USAP $(\mathrm{r}=0.51, \mathrm{p}=0.022)$; no relation was found between other cardiac biomarker levels at admission $(\mathrm{p}>0.05)$.

The relation between CK-MB, cTnI, Gal-3 and H-FABP levels at the $2^{\text {nd }}$ hour in each study group is shown in Table 3.

There was a strong and positive, statistically significant relation between cTnI and CK-MB levels at the 2nd hour in patients with STEMI $(r=0.80, p<0.001)$; no relation was found between other cardiac biomarker levels at the 2 nd hour $(\mathrm{p}>0.05)$. There was a strong and positive, statistically significant relation between cTnI and CK-MB levels at the 2nd hour in patients with NSTEMI $(\mathrm{r}=0.83, \mathrm{p}<0.001)$; no relation was found between other cardiac biomarker levels at the 2 nd hour $(\mathrm{p}>0.05)$.

There was a strong and moderate, statistically significant relation between $\mathrm{cTnI}$ and $\mathrm{H}-\mathrm{FABP}$ levels at the $2 \mathrm{nd}$ hour in patients with USAP $(r=0.46 ; p=0.040)$; no relation was found between other cardiac biomarker levels at the 2 nd hour $(p>0.05)$.

The relation between CK-MB, cTnI, Gal-3 and H-FABP levels at the 4th hour in each study group is shown in Table 4.

There was a moderate and positive, statistically significant relation between cTnI and CK-MB levels at the 4th hour in patients with STEMI $(r=0.78, p<0.001)$; no relation was found between other cardiac biomarker levels at the 4 th hour $(p>0.05)$.
There was a positive and statistically significant relation between cTnI and both CK-MB and Gal-3 levels at the 4th hour in patients with NSTEMI $(r=0.76 ; p<0.001, r=0.64 ; p<0.002)$; no relation was found between other cardiac biomarker levels at the 4th hour $(\mathrm{p}>0.05)$. No relation was found between CKMB, cTnI, Gal-3 and H-FABP levels at 4th hour in patients with $\operatorname{USAP}(\mathrm{p}>0.05)$.

\section{Discussion}

It is important to diagnose ACS in the early period to reduce both mortality and morbidity in patients admitted to emergency room with chest pain. Therefore, new cardiac biomarkers are needed to diagnose ACS in earlier time. By diagnosing ACS with these cardiac biomarkers in the earlier period, mortality and morbidity rates can be reduced and accumulation of these patients in emergency rooms can be prevented. In this study, we investigated whether Gal-3 and H-FABP could be used as new cardiac biomarkers in the diagnosis of ACS in the early period, and whether they were superior to $\mathrm{CK}-\mathrm{MB}$ and $\mathrm{cTnI}$ in patients, who were thought to have ACS.

Considering the tissue specificity and improved sensitivity that cardiac troponins have, measurement of these is the most frequently used method in the diagnosis of ACS in patients with chest pain, but the diagnostic specificity and sensitivity of cardiac

Tab. 4. The relationship between CK-MB, cTnI, Galectin-3 and HFABP levels at 4th hour within each study group.

\begin{tabular}{|c|c|c|c|c|c|c|}
\hline 4.hour & & & CK-MB & CTnI & Gal-3 & H-FABP \\
\hline \multirow{8}{*}{$\begin{array}{l}\text { USAP } \\
(n=20)\end{array}$} & \multirow{2}{*}{ CK-MB } & $\mathrm{r}$ & 1.000 & 0.124 & 0.100 & -0.411 \\
\hline & & $\mathrm{p}$ & . & 0.602 & 0.675 & 0.072 \\
\hline & \multirow{2}{*}{ cTnI } & $\mathrm{r}$ & 0.124 & 1.000 & -0.099 & 0.189 \\
\hline & & $\mathrm{p}$ & 0.602 & . & 0.678 & 0.425 \\
\hline & \multirow{2}{*}{ Gal-3 } & $\mathrm{r}$ & 0.100 & -0.099 & 1.000 & 0.426 \\
\hline & & $\mathrm{p}$ & 0.675 & 0.678 & . & 0.061 \\
\hline & \multirow{2}{*}{ H-FABP } & $\mathrm{r}$ & -0.411 & 0.189 & 0.426 & 1.000 \\
\hline & & $\mathrm{p}$ & 0.072 & 0.425 & 0.061 & . \\
\hline \multirow{8}{*}{$\begin{array}{l}\text { STEMI } \\
(\mathrm{n}=20)\end{array}$} & \multirow{2}{*}{ CK-MB } & $\mathrm{r}$ & 1.000 & $0.780^{* *}$ & -0.164 & 0.014 \\
\hline & & $\mathrm{p}$ & . & $<0.001$ & 0.491 & 0.954 \\
\hline & \multirow{2}{*}{ cTnI } & $\mathrm{r}$ & $0.780^{* * *}$ & 1.000 & -0.163 & -0.009 \\
\hline & & $\mathrm{p}$ & $<0.001$ & . & 0.493 & 0.969 \\
\hline & \multirow{2}{*}{ Gal-3 } & $\mathrm{r}$ & -0.164 & -0.163 & 1.000 & 0.077 \\
\hline & & $\mathrm{p}$ & 0.491 & 0.493 & . & 0.748 \\
\hline & \multirow{2}{*}{ H-FABP } & $\mathrm{r}$ & 0.014 & -0.009 & 0.077 & 1.000 \\
\hline & & $\mathrm{p}$ & 0.954 & 0.969 & 0.748 & . \\
\hline \multirow{8}{*}{$\begin{array}{l}\text { NSTEMI } \\
(\mathrm{n}=20)\end{array}$} & \multirow{2}{*}{ CK-MB } & $\mathrm{r}$ & 1.000 & $0.758^{* *}$ & 0.314 & 0.313 \\
\hline & & $\mathrm{p}$ & . & $<0.001$ & 0.177 & 0.179 \\
\hline & \multirow{2}{*}{ cTnI } & $\mathrm{r}$ & $0.758^{* *}$ & 1.000 & $0.641^{* *}$ & 0.199 \\
\hline & & $\mathrm{p}$ & $<0.001$ & . & 0.002 & 0.399 \\
\hline & \multirow{2}{*}{ Gal-3 } & $\mathrm{r}$ & 0.314 & $0.641^{* *}$ & 1.000 & -0.066 \\
\hline & & $\mathrm{p}$ & 0.177 & 0.002 & . & 0.782 \\
\hline & \multirow{2}{*}{ H-FABP } & $\mathrm{r}$ & 0.313 & 0.199 & -0.066 & 1.000 \\
\hline & & $\mathrm{p}$ & 0.179 & 0.399 & 0.782 & . \\
\hline
\end{tabular}

r:Spearman Correlation Coefficient 
troponins during the first hour of the pain are insufficient (7-9). Therefore, new cardiac biomarkers are needed in the early diagnosis of ACS.

Approaches evaluating more than one biomarker instead of one biomarker are reported to be more useful in diagnosing and excluding ACS $(10,11)$. The plasma levels of CK-MB and troponins begin to increase within 3-4 hours and myoglobin within 1 hour after the onset of myocardial damage. However, myoglobin in not specific for myocardium and CK-MB and troponin levels do not increase in plasma in the early stages of ischemia, which means that they do not contribute to the early detection of myocardial damage (12-14). As the result of our study, we found that patients with USAP did not have an increase in cTnI plasma levels at admission, and the 2 nd and 4 th hours, but a significant increase in plasma cTnI levels was detected in patients with STEMI and NSTEMI. According to this finding, an increase in cTnI levels in patients with STEMI and NSTEMI may be an important indicator in diagnosis. The diagnosis of NSTEMI is made by showing an increase in serum levels of cardiac biomarkers showing myocardial necrosis because there is no ST elevation in ECG in NSTEMI (15).

A release of H-FABP from damaged myocardium was first described in 1988 (16). Since then, various studies were carried out for the use of biochemical markers of myocardial injury in the clinical practice. After the detection of H-FABP as a sensitive and an early marker of myocardial damage, further studies have been conducted using other FABP types in determining and monitoring tissue damage $(17,18)$. Alhadi et al reported that the H-FABP level at admission had the highest sensitivity in the diagnosis of ACS (19). Nakata et al and O'Donoghue et al. showed that HFABP was an early diagnostic and prognostic marker in ACS, and H-FABP levels began to rise in plasma 1-3 hours following initial ACS symptoms $(20,21)$. Gerede et al compared H-FABP with CK-MB and cTnI and showed that there was no difference between their specificities at $0-4$ hours in the diagnosis of NSTEMI, but H-FABP had the highest sensitivity and there was no difference in sensitivity and specificity for the 3 markers after the 6 th hour (22). We found statistically significant differences between the groups in terms of H-FABP levels at admission, and the 2nd and 4th hours. We showed that the differences originated from the NSTEMI group. The serum H-FABP levels of the patients in the NSTEMI group were found to be low. We assume that this was due to early admission to the emergency room, and less myocardial damage in the patients with NSTEMI compared with the patients with STEMI. We believe that our findings on H-FABP in patients with NSTEMI should be supported by further studies.

USAP has the most subjective diagnostic criteria among ACSs (23). Although there are not a large number of studies related to USAP and H-FABP in literature, Alnsari et al reported that H-FABP values supported the clinical findings in patients with chest pain (24). Alhadi et al reported that H-FABP levels at admission, and the 2nd and 4th hours were significantly higher than CK-MB and cTnI levels in the early diagnosis of USAP (19). In our study, we found a positive and strong relation between cTnI and H-FABP levels at admission, and positive and moderate relation between
cTnI and H-FABP levels at the 2nd hour in patients with USAP. There was no difference between CK-MB, cTnI, and H-FABP levels at the 4th hour in patients with USAP. In addition, there was no difference between H-FABP levels at admission, and the 2nd and 4th hours in patients with USAP. We believe that the findings on H-FABP in patients with USAP should be supported by further studies.

Among the ACSs, STEMI has the highest mortality rate. Patients are characterized by increases and decreases in levels of cardiac biomarkers reflecting myocardial damage, changes in successive ECG recordings, and prolonged chest pain for more than 30 minutes (25). In the study of Yoshihiko et al, H-FABP levels were reported to be more diagnostic than troponin $\mathrm{T}$ in the patients with STEMI (26). Rüzgar et al reported that H-FABP was more sensitive in the first 6 hours in the patients with STEMI (27). In our study, there was no statistically significant difference between H-FABP levels at admission, and the 2nd and 4th hours in the patients with STEMI. There is little research on H-FABP in the patients with STEMI because early diagnosis is made using ECG and there is no need to wait for cardiac marker results. Gerede et al. reported that waiting for cardiac marker resulted in delayed diagnosis and treatment in STEMI (22). In our study, patients with STEMI were enrolled in coronary angiography based on ECG findings without waiting for cardiac marker results as indicated by Gerede et al. The first blood samples were taken at the time of admission and the follow-up was performed in the intensive care unit after coronary angiography. We believe that the lack of difference between H-FABP levels at admission, and the 2nd and 4th hours in patients with STEMI was due to the rapid enrollment of patients in coronary angiography as soon as the diagnosis was made based on ECG, and as the result, minimal ischemia in cardiac myocytes.

Gal-3 has important pathophysiologic effects on the development and progression of heart failure (HF) by causing fibrosis and inflammation. Several studies have shown up-regulation of Gal-3 in left ventricular hypertrophy. Gal-3 acts by causing fibroblast proliferation and fibrosis, which occurs following macrophage migration. The myocardial up-regulation effect of Gal-3 has been shown in animal study prototypes such as: hypertensive rat prototype with a predisposition to $\mathrm{CF}$, streptozotocin-induced diabetic cardiomyopathy, interferon $\gamma$-induced cardiomyopathy, and chronic active myocarditis in rats. The relationship between macrophage activation and myocardial up-regulation led by Gal3 was determined in these study prototypes (28-30). Lisowska et al indicated that Gal-3 levels increased slightly in patients with ACS compared with the control group. They assumed that this could be due to prior ischemic heart disease, hypertension, diabetes mellitus, dyslipidemia or severe coronary atherosclerosis in those patients. The authors reported no difference between the patients with NSTEMI and STEMI in terms of Gal-3 levels. However, there was no comparison made between Gal-3 and cardiac troponin levels (31). Sharma et al reported that the increase in Gal-3 levels in patients with ACS was associated with co-morbid major adverse cardiovascular events in such patients. They also reported that serum Gal-3 level was associated with 
cardiac remodeling after ischemia and might be effective in determining adverse cardiovascular outcomes after ACS (32). Erlend et al reported no changes in serial measurements of serum Gal-3 levels in STEMI (33). Van Kimmenade et al and Lok et al showed that increased levels of Gal-3 could be a useful biomarker in the diagnosis and predicting prognosis of HF $(34,35)$. Chen et al suggested that increased Gal-3 levels were associated with the mortality rate of acute and chronic HF (36). We found statistically significant changes between all the three groups in terms of Gal-3 levels at admission, and the 2nd and 4th hours. We also found that the change in Gal-3 levels was more significant in patients with STEMI and NSTEMI than in patients with USAP. This could be due to the earlier admission of patients with USAP to the emergency room, and as the result, less damage in cardiac myocytes. Also, we found no difference between Gal-3 levels at admission, and the 2 nd and 4 th hours within each group. Our results suggest that Gal-3 could be used in the diagnosis of STEMI and NSTEMI.

\section{Conclusions}

According to our results, cTnI, H-FABP, and Gal-3 are useful parameters in the early diagnosis of ACS. We found an increase in cTnI levels from admission to the 4th hour, but no increase in H-FABP and Gal-3 levels from admission to the 4th hour.

\section{References}

1. Antman EM, Braunwald E. Acute moycardial infarction. In: Braunwald E, Zipes D, Libby P, eds. Heart Disease. Ed: A textbook of cardiovascular medicine. Philadelphia: WB Saunders company 2001; 1131-1135.

2. Safford MM, Parmar G, Barasch CS et al. Hospital laboratory reporting may be a barrier to detection of 'microsize' myocardial infarction in the US: an observational study. BMC Health Serv Res. 2013; 13: 162.

3. Üstündağ M, Orak M, Güloğlu C et al. Comparative diagnostic accuracy of serum levels of neutrophil activating peptide-2 and pentraxin-3 versus troponin-1 in acut coronary syndrome. Anadolu Kardiol Derg 2011; 11: $588-594$.

4. Wang J, Tan GJ, Han LN et al. Novel biomarkers for cardiovascular risk prediction. Journal of geriatric cardiology: JGC 2017; 14: 135.

5. Maiolino G, Rossitto G, Pedon L et al. Galectin-3 predicts long-term cardiovascular death in high-risk patients with coronary artery disease. Arterioscler Thromb Vasc Biol. 2015; 35: 725-732.

6. Lisowska A, Knapp M, Tycinska A et al. Predictive value of galectin-3 for the occurrence of coronary artery disease and prognosis after myocardial infarction and its association with carotid imt values in these patients: a mid-term prospective cohort study. Atherosclerosis. 2016; 246 : 309-317.

7. Lippi G, Montagnana M, Salvagno GL, Guidi GC. Potential value for new diagnostic markers in the early recogntion of acute coreonary syndromes. Can J Emerg Med 2006; 8: 27-31.

8. Wudkowska A, Goch J, Goch A. Ischemia-modified albumin in differential diagnosis of acute coronary syndrome without ST elevation and unstable angina pectoris. Kardiologia Polska 2010; 68: 431-437.
9. Kume N, Mitsuoka H, Hayashida K, Tanaka M. Pentraxin 3 as a biomarker for acute coronary syndrome: Comparison with biomarkers for cardiac damage. Journal of Cardiology 2011; 58: 38-45.

10. Kontos MC, Anderson FP, Hanbury CM et al. Use of the combination of myoglobin and CK-MB mass for the rapid diagnosis of acute myocardial infarction. Am J Emerg Med 1997; 15: 14-19.

11. Newby LK, Storrow AB, Gibler WB et al. Bedside multimarker testing for risk stratification in chest pain units: The chest pain evaluation by creatine kinase-MB, myoglobin, and troponin I (CHECKMATE) study. Circulation 2001; 103: 1832-1837.

12. Mair J, Artner-Dworzak E, Lechleitner $P$ et al. Early diagnosis of acute myocardial infarction by a newly developed rapid immunoturbidimetric assay for myoglobin. Br Heart J 1992; 68: 462-468.

13. Zimmerman J, Fromm R, Meyer D et al. Diagnostic marker cooperative study for the diagnosis of myocardial infarction. Circulation 1999; 99: 1671-1677.

14. Mair J, Morandell D, Genser $\mathbf{N}$ et al. Equivalent early sensitivities of myoglobin, creatine kinase MB mass, creatine kinase isoform ratios and cardiac troponins I and T for acute myocardial infarction. Clin Chem1995; 41: $1266-1272$.

15. Cannon CP, Weintraub WS, Demopoulos LA et al. TACTICS (Treat Angina with Aggrastat and Determine Cost of Therapy with an Invasive or Conservative Strategy)-Thrombolysis in Myocardial Infarction 18 Investigators. Comparison of early invasive and conservative strategies in patients with unstable coronary syndromes treated with the glycoprotein IIb/IIIa inhibitor tirofiban. N Engl J Med 2001; 344: 1879-1887.

16. Glatz JF, van Bilsen M, Paulussen RJ et al. Release of fatty acidbinding protein from isolated rat heart subjected to ischemia and reperfusion or to the calcium paradox. Biochim Biophys Acta. 1988; 961: 148-152.

17. Pelsers MM, Hermens WT, Glatz JF. Fatty acid-binding proteins as plasma markers of tissue injury. Clin Chim Acta. 2005; 352: 15-35.

18. Wunderlich MT, Hanhoff T, Goertler M et al. Release of brain-typeand heart-type fatty acid-binding proteins in serumafter acute ischaemic stroke. J Neurol. 2005; 252: 718-724.

19. Alhadi HA, Keith AA. Fox Heart-Type Fatty Acid-Binding Protein in the Early Diagnosis of Acute Myocardial Infarction. SQU Med J 2010; 10: 41-49.

20. Nakata T, Hashimoto A, Hase M et al. Human heart-type fatty acidbinding protein as an early diagnostic and prognostic marker in acute coronary syndrome. Cardiology 2003; 99: 96-104.

21. O'Donoghue M, de Lemos JA, Morrow DA et al. Prognostic utility of heart-type fatty acid binding protein in patients with acute coronary syndromes. Circulation 2006; 114: 550-557.

22. Gerede DM, Güleç S, Kiliçkap M et al. Comparison of a qualitative measurement of heart-type fatty acid-binding protein with other cardiac markers as an early diagnostic marker in the diagnosis of non-stsegment elevation myocardial infarction. Cardiovasc J Afr 2015; 26: 204-209.

23. Braunwald E. Unstable angina. A classification. Circulation 1989; 80: 410-414.

24. Alnsari SE, Croal BL. Diagnostic value of heart fatty acid binding protein and myoglobin in patients admitted with chest pain. Ann Clin Biochem 2004; 41: 391-396.

25. Braunwald E, Jones RH, Mark DB et al. Diagnosing and managing unstable angina. Agency for Health Care Policy and Research. Circulation 1994; 90: 613-622. 


\section{4-130}

26. Yoshihiko S, Tomita Y, Takano T, Ohbayashi K; Tokyo Rapid-Test Office Cardiologists (Tokyo-ROC) study. Office cardiologists cooperative study on whole blood rapid panel tests in patients with suspicious acute myocardial infarction. Circ J 2004; 68: 144-148.

27. Ruzgar O, Bilge AK, Bugra $\mathbf{Z}$ et al. The use of human heart-type fatty acid-binding protein as an early diagnostic biochemical marker of myocardial necrosis in patients with acute coronary syndrome, and its comparison with troponin-T and creatine kinase-myocardial band. Heart Vessels 2006; 21: 309-314.

28. Sharma UC, Pokharel S, van Brakel TJ et al. Galectin-3 marks activated macrophages in failure-prone hypertrophied hearts and contributes to cardiac dysfunction. Circulation 2004; 110: 3121-3128.

29. Reifenberg K, Lehr HA, Torzewski M et al. Interferon $\gamma$ induces chronic active myocarditis and cardiomyopathy in transgenic mice. Am J Pathol 2007; 171: 463-472.

30. Thandavarayan RA, Watanabe K, Ma M et al. 14-3-3 Protein regulates Ask1 signaling and protects against diabetic cardiomyopathy. Biochem Pharmacol 2008; 75: 1797-1806.

31. Lisowska A, Knapp M, Tycińska A et al. Predictive value of Galectin-3 for the occurrence of coronary artery disease and prognosis after myocardial infarction and its association with carotid IMT values in these patients: A mid-term prospective cohort study. Atherosclerosis 2016; 246 : 309-317.

32. Sharma UC, Mosleh W, Chaudhari MR et al. Myocardial and Serum Galectin-3 Expression Dynamics Marks Post-Myocardial Infarction Cardiac Remodelling. Heart Lung Circ 2017; 26: 736-745.

33. Singsaas EG, Manhenke CA, Dickstein K et al. Galectin-3 Levels Are Increased in Patients with Ischemic Heart Disease, but Are Not Influenced by Acute Myocardial Infarction. Cardiology 2016; 134: 398-405.

34. Van Kimmenade RR, Januzzi JL, Jr. Ellinor PT et al. Utility of amino-terminal pro-brain natriuretic peptide, galectin-3, and apelin for the evaluation of patients with acute heart failure. J Am Coll Cardiol 2006; 48: 1217-1224.

35. Lok DJ, Van Der Meer P, de la Porte PW et al. Prognostic value of galectin-3, a novel marker of fibrosis, in patients with chronic heart failure: data from the deal-hf study. Clin Res Cardiol 2010; 99: 323-328.

36. Chen YS, Gi WT, Liao TY et al. Using the galectin-3 test to predict mortality in heart failure patients: a systematic review and meta-analysis. Biomark Med 2016; 10: 329-342. 